\title{
Randomised controlled trial of paracetamol for heel prick pain in neonates
}

\author{
Vibhuti Shah, Anna Taddio, Arne Ohlsson
}

\begin{abstract}
Aim-To evaluate the effectiveness of paracetamol in decreasing the pain from heel prick.

Methods-A prospective randomised double blind placebo controlled trial was conducted of 75 term neonates undergoing heel prick. Sixty to 90 minutes before the procedure neonates received paracetamol orally in a dose of $20 \mathrm{mg} / \mathrm{kg}$ (group 1) or an equal volume of placebo (group 2). Heel prick was performed in a standardised manner. Pain assessments were made using per cent facial action (brow bulge, eye squeeze, and nasolabial fold (range $0-300 \%)$ and per cent of time spent crying (range 0-100\%).

Results-Thirty eight neonates were enrolled in group 1 and 37 neonates in group 2. There were no significant differences in the demographic characteristics between groups. Mean gestational age was 39 (SD 1.4) vs 39.4 (SD 1.2) weeks, $\mathrm{p}=0.86$, mean birthweight 3.45 (SD 0.45) vs 3.44 (SD $0.42) \mathrm{kg}$; $\mathrm{p}=0.31$ for groups 1 and 2 , respectively. Facial action pain scores did not differ between groups (143.5 (SD $54.2) \%$ vs 131.1 (SD 59.6)\%; $\mathrm{p}=0.38$ ). Cry scores also did not differ (29.4 (SD 19.9)\% vs 26.8 (SD 20.2)\%; $\mathrm{p}=0.60$ ). No adverse effects were observed.

Conclusion-Paracetamol is ineffective for decreasing the pain from heel prick in term neonates.
\end{abstract}

(Arch Dis Child Fetal Neonatal Ed 1998;79:F209-F211)

Keywords: pain; heel prick; paracetamol

Heel prick is routinely performed on neonates for the screening of treatable diseases such as hypothyroidism and phenylketonuria. ${ }^{1} \mathrm{Ne}-$ onates undergoing this procedure $\mathrm{cry}^{2}$ and exhibit facial expressions ${ }^{3-7}$ and body movements ${ }^{8}$ which are indicative of extreme pain. However, analgesics are rarely administered. Recent research suggests that babies' early pain experience may adversely affect their pain response in later infancy. ${ }^{9-10}$ There is growing awareness that neonatal pain should be treated, yet surprisingly little research has been done on pharmacological interventions to decrease procedural pain.

Paracetamol is an antipyretic and analgesic drug without anti-inflammatory effects. It is routinely used in neonates and is considered safe. ${ }^{11}$ To our knowledge there has not been any study on the efficacy of paracetamol for acute pain relief for procedures such as heel prick. The objective of this study was to evaluate the efficacy of paracetamol as an analgesic in neonates subjected to heel prick.

\section{Methods}

The study was approved by the hospital research ethics committee and informed parental consent was obtained for all participants. Healthy full term neonates $\geqslant 37$ weeks of gestation undergoing heel prick for screening of newborn diseases were recruited. Using a computer generated random numbers list, neonates were randomised by the pharmacy department to receive oral paracetamol cherry elixir $(32 \mathrm{mg} / \mathrm{ml})$ in a dose of $20 \mathrm{mg} / \mathrm{kg}$ or an equal volume of placebo (cherry elixir) of identical appearance before heel prick. The exact dose of paracetamol or placebo (McNeil Consumers Products Company, Guelph, Ontario) was measured using a $3 \mathrm{cc}$ syringe. The study drug was administered 60-90 minutes before the procedure. One investigator (VS) performed all heel pricks using a $0.5 \mathrm{~cm}$ lancet (Microlance 3C610, Becton-Dickinson, Canada). The heel prick procedure comprised four phases: baseline; heel pricking; squeezing the heel (blood collection); and return to baseline (recovery phase). Neonates were videotaped throughout the entire procedure and for three minutes during the recovery phase. Pain assessments were subsequently made from the videotapes by a research assistant blinded to treatment allocation. Outcome measures included infant facial activity and cry duration. The presence or absence of three distinct facial actions (brow bulge, nasolabial fold, eyes squeezed shut) was scored in one second intervals for each phase of the procedure. Data were then collapsed into per cent of time each facial action was observed. An overall facial pain score was obtained by summing the individual scores for each facial action. The score ranged from $0-300 \%$. Brow bulge, eye squeeze, and nasolabial furrowing were chosen for the study because these facial actions have been observed in $99 \%$ of neonates within six seconds of heel prick and are believed to be the most sensitive indicators of infant pain. ${ }^{4}$ The proportion of time spent crying was also calculated from the videotape and ranged from $0-100 \%$. Demographic characteristics, including gestational age, birthweight, postnatal age, gender, type of delivery, infant state (active awake, active asleep, quiet awake, quiet asleep) were collected on a standardised data collection form. The number of pricks required to collect the sample and any other painful procedure experienced by the neonate before study entry, such as circumcision, were recorded.

To achieve a clinically significant reduction in pain scores between groups (20\%), with 
Table 1 Demographic characteristics of study subjects *

\begin{tabular}{llll}
\hline & $\begin{array}{l}\text { Group 1 }(n=38)+ \\
\text { (paracetamol) }\end{array}$ & $\begin{array}{l}\text { Group 2 } \\
\text { (placebo) }\end{array}$ & p Value \\
\hline Gestational age (weeks) & $39.5(1.4)$ & $39.4(1.2)$ & 0.86 \\
Birthweight (kg) & $3.45(0.45)$ & $3.55(0.42)$ & 0.31 \\
Postnatal age (hours) & $34.8(10.1)$ & $36.9(10.3)$ & 0.36 \\
Apgar score at 1 minute & $8.3(1.0)$ & $8.4(0.9)$ & 0.21 \\
Apgar score at 5 minutes & $8.9(0.3)$ & $9.0(0.2)$ & 0.60 \\
Gender (male) & $21(55 \%)$ & $21(57 \%)$ & 1.0 \\
Medication vomited & $7(18 \%)$ & $4(11 \%)$ & 0.51 \\
Vaginal delivery (n) & 32 & 28 & 0.37 \\
\hline
\end{tabular}

* Figures are mean (SD) or number (\%).

$\dagger 4$ boys in group 2 were circumcised before study entry and two infants in each group had previous heel pricks.

$80 \%$ power and a $\mathrm{p}$ value of $<0.05$, we estimated a sample size of 35 babies in each group. This sample size was based on pain scores obtained for heel prick from our previous study. ${ }^{12}$ The total sample size was increased to 75 neonates to account for possible dropouts and missing data, such as video recording errors.

Demographic characteristics and pain assessments were compared between groups using $\chi^{2}$ analysis or Fischer's exact test for categorical data and Student's $t$ test for continuous data. The effect of infant characteristics on pain scores was assessed using linear regression. A p value of $<0.05$ was considered significant.

\section{Results}

Seventy five neonates were enrolled; 38 in the paracetamol (group 1) and 37 in the placebo (group 2) group. There were no significant differences between groups in terms of demographic characteristics (table 1).

Ten infants were excluded from the efficacy analysis. In nine cases the infants had multiple heel pricks ( $n=5$, group $1 ; n=4$, group 2 ) and in one case the video recording was of poor quality (group 1). Facial action scores during heel prick did not differ between groups 1 and 2 ( $143.5 \%$ vs $131.1 \% ; \mathrm{p}=0.38)$. The proportion of time infants spent crying did not differ (29.4\% vs $26.8 \%$; $p=0.60)$ between groups. When individual phases of the heel prick were compared between groups, again no differences were observed (table 2). The results did not change when infants in the paracetamol group who vomited part of the dose were excluded from the analysis.

Infant characteristics (gestational age, gender, birthweight, age at the time of study, infant state and time of feeding before heel prick) did

Table 2 Pain scores during heel pricks for paracetamol and placebo groups*

\begin{tabular}{|c|c|c|c|}
\hline & $\begin{array}{l}\text { Group } 1(n=32) \\
\text { (paracetamol) }\end{array}$ & $\begin{array}{l}\text { Group } 2(n=33) \\
\text { (placebo) }\end{array}$ & $p$ Value \\
\hline \multicolumn{4}{|l|}{ Facial action (\%) } \\
\hline Baseline & $22.2(39.5)$ & $30.2(55.1)$ & 0.50 \\
\hline Heel prick (overall) & $143.5(54.2)$ & $131.1(59.6)$ & 0.38 \\
\hline Prick phase & $174.2(64.2)$ & $184.0(64.9)$ & 0.54 \\
\hline Squeeze phase & $227.6(44.7)$ & $203.6(75.2)$ & 0.12 \\
\hline Recovery phase & $73.3(74.2)$ & $57.8(71.5)$ & 0.39 \\
\hline \multicolumn{4}{|l|}{ Cry (\%) } \\
\hline Baseline & $0.0(0)$ & $1.3(7.7)$ & 0.33 \\
\hline Heel prick (overall) & $29.4(19.9)$ & $26.8(20.2)$ & 0.60 \\
\hline Prick phase & $37.3(30.6)$ & $39.3(29.4)$ & 0.79 \\
\hline Squeeze phase & $51.4(27.1)$ & $44.3(30.5)$ & 0.32 \\
\hline Recovery phase & $10.1(18.5)$ & $8.7(21.3)$ & 0.78 \\
\hline
\end{tabular}

^ Figures are mean (SD). not affect per cent cry scores $(p>0.05)$. Infant state and gestational age did, however, significantly affect per cent facial action scores $(p<0.05)$. Infants of younger gestational age exhibited fewer facial actions than older infants. Infants in awake states exhibited more facial actions than those in sleep states. No adverse effects were observed during the study period.

\section{Discussion}

Pharmacological interventions are infrequently used for procedural pain due to concerns about adverse effects and a lack of conviction among caregivers that pain is important for the neonate's present or future wellbeing. We studied paracetamol because its safety in the neonatal period has been well established. This study failed to demonstrate any analgesic effect of paracetamol on heel prick in neonates.

To establish the effectiveness of an analgesic agent a reduction in the level of pain perceived must be shown. In older children and adults this can be achieved by asking patients how much pain they feel. Self report is not possible in neonates and we rely on observational techniques to deduce their pain experience. Cry, facial activity, body movement and physiological changes are commonly used to infer the magnitude of pain. We used cry and facial actions to measure infant pain. We found no difference in the per cent facial actions or cry among neonates treated with paracetamol or placebo. Infants' facial actions were affected by gestational age and the infant's state. Previous studies have also found that these variables influence facial activity during heel prick. ${ }^{13}{ }^{14}$

One possible explanation for the observed failure of paracetamol to control the pain from heel prick is that the pain may be intense. Paracetamol is considered to have only mild to moderate analgesic activity. The mechanism of action of paracetamol is not fully known, although it is believed to act centrally to inhibit the cyclo-oxygenase pathway and the release of nociceptive neurotransmitters. ${ }^{15}$ As paracetamol does not block the activation of afferent pain fibres directly, we assessed whether it could influence the pain after the heel prickthat is, during the recovery phase. However, we found no differences between groups. Another possible explanation for the lack of efficacy of paracetamol is that patients may not have achieved therapeutic concentrations. The plasma concentration corresponding to an analgesic effect has not been determined in children but is believed to be $5-20 \mathrm{mg} / \mathrm{l} .{ }^{16}$ We did not measure the plasma concentrations of paracetamol, but administered a dose of 20 $\mathrm{mg} / \mathrm{kg} 60$ to 90 minutes before the heel prick. Previous studies have shown that peak plasma concentrations are achieved within this time frame. ${ }^{17}$

Only two studies have assessed the efficacy of paracetamol in neonates before. Howard et $a l^{18}$ showed that paracetamol $15 \mathrm{mg} / \mathrm{kg}$ orally two hours before circumcision and then every six hours did not ameliorate the intraoperative or immediate postoperative pain compared to placebo. Infant pain was assessed using heart 
rate, respiratory rate, crying time and a standardised comfort scoring system. Paracetamol was, however, associated with lower comfort scores six hours after surgery. Van Lingen $e t a l^{19}$ (data published in abstract form) assessed the effectiveness of paracetamol for relief of pain and associated symptoms in neonates who experienced a vacuum extraction delivery. Paracetamol $(20 \mathrm{mg} / \mathrm{kg})$ or placebo was administered rectally every six hours after birth. Clinical symptoms (vomiting, poor feeding, pain on handling, abdominal distension, irritability and grunting) and "facies pain" were reduced after the first dose, but not with subsequent doses. It was not clear why only the first dose was effective. Paracetamol was administered rectally, and delayed or incomplete $^{20}$ absorption could have contributed to the lack of response.

A wide variety of non-pharmacological and pharmacological interventions has been investigated for the management of pain of heel prick, such as automated piercing devices, ${ }^{21}$ behavioural interventions such as pacifiers ${ }^{22}$ and rocking, ${ }^{23}$ sucrose, ${ }^{24}$ non-sucrose sweet tasting solution ${ }^{25}{ }^{26}$ and local anaesthetic cream such as lignocaine ${ }^{27}$ and EMLA. ${ }^{28}{ }^{29}$ Autolet, a mechanical lancet, caused less pain than manual heel prick when used to collect blood in neonates. ${ }^{21}$ Comforting methods such as use of pacifier and rocking were associated with reduced crying. ${ }^{22}{ }^{23} \mathrm{~A}$ recent meta-analysis on the efficacy of sucrose for relieving procedural pain showed that $0.24 \mathrm{~g} \mathrm{(} 2 \mathrm{ml}$ of $12 \%$ sucrose solution) administered orally two minutes before heel prick significantly reduced pain. ${ }^{24}$ Other sweet tasting solutions such as hydrogenated glucose syrup $^{25}$ and $30 \%$ glucose solution ${ }^{26}$ have been associated with lower pain scores. Studies of five per cent lignocaine ointment and EMLA cream, on the other hand, have not demonstrated a decrease in pain response to heel prick. ${ }^{27-29}$ The ineffectiveness of local anaesthetics may be related to failure to penetrate the skin to an adequate depth to allow blocking of nerve endings or increased uptake into the systemic circulation.

In conclusion, paracetamol is ineffective for treatment of pain from heel lance.

This study was partly funded by McNeil Consumers Products Company, Guelph, Ontario, Canada.

1 Miller J. Reflections on research involving children. National Council on Bioethics in Human Research. Ottawa: Medical Research Council of Canada,1993.
2 Owens ME, Todt EH. Pain in infancy: neonatal reaction to a heel lance. Pain 1994;20:77-86.

3 Izard CE. The maximally discriminative facial movement coding system $(M A X)$. Newark, DE: University of Delaware Instructional Resources Centre, 1979

4 Grunau RVE, Craig KD. Pain expression in neonates: facial action and cry. Pain 1987;28:395-410.

5 Izard CE, Huebner RR, Risser D. The infant's ability to produce discrete emotional expressions. Dev Psychol 1980;16:132-40.

6 Ekman P, Friesen WV. Manual for the Facial Action Coding System (FACS). Palo Alto, CA: Consulting Psychologists Press, 1978.

7 Johnston CC, Strada ME. Acute pain response in infants: a multidimensional description. Pain 1986;24:373-82.

8 Franck LS. A new method to quantitatively describe pain behaviour in infants. Nurs Res 1986;35:28-31.

9 Taddio A, Goldbach M, Ipp M, Stevens B, Koren G. Effect of neonatal circumcision on pain responses during vaccination in boys. Lancet 1995;345:291-2

10 Taddio A, Katz J, Ilersich AL, Koren G. Effect of neonatal circumcision on pain response during subsequent routine circumcision on pain response during sub
vaccination. Lancet 1997;349:599-603.

11 Anand KJS, Mc Grath PJ. Pain in neonates. In: Pain esearch and clinical management. Amsterdam: Elsevier, 1993:158.

12 Shah VS, Taddio A, Bennett S, Speidel BD. Neonatal pain response to heel stick vs venepuncture for routine blood sampling. Arch Dis Child 1997;77:143-4.

13 Craig KD, Whitfield MF, Grunau RVE, Linton J, Hadjistavropoulos HD. Pain in the preterm neonate: behavioural and physiological indices. Pain 1993;52:287-99.

14 Grunau RVE, Craig KD. Pain expression in neonates: facial action and cry. Pain 1987;28:395-410.

15 Piletta P, Porchet HC, Dayer P. Central analgesic effect of acetaminophen but not of aspirin. Clin Pharmacol Ther 1991;49:350-4

16 Jackson CH, Mac Donald NC, Cornett JWD. Acetaminophen: a practical pharmacologic overview. Can Med Assoc F 1984;131:25-32.

17 Hopkins CS, Underhill S, Booker PD. Pharmacokinetics of paracetamol after cardiac surgery. Arch Dis Child 1990;65:971-6.

18 Howard CR, Howard FM, Wietzman ML. Acetaminophen analgesia in neonatal circumcision: The effect on pain. Pediatrics 1994;93:641-6.

19 Van Lingen R, Quak C, Deinum H, van de Logt F, Eyek J, Okken A. Clinical effects of rectally administered acetaminophen (APAP) on infants delivered by vacuum extraction. Pediatr Res 1995;38:458.

20 Miller RP, Roberts RJ, Fischer LJ. Acetaminophen elimination kinetics in neonates, children and adults. Clin Pharmacol Ther 1976;19:284-94.

21 Harpin VA, Rutter N. Making heel pricks less painful. Arch Dis Child 1983; 58:226-8.

22 Field T, Goldson E. Pacifying effects of non-nutritive sucking on term and preterm neonates during heel stick procedures. Pediatrics 1984;74:1012-5.

23 Campos GR. Rocking and pacifiers: Two comforting interventions for heel stick pain. Res Nurs Health 1994;17:32131.

24 Stevens B, Taddio A, Ohlsson A, Einarson T. The efficacy of sucrose for relieving procedural pain in neonates - a systematic review and meta-analysis. Acta Paediatr Scand 1997;86:837-42.

25 Ramenghi LA, Griffiths GC, Wood CM, Levene MI. Effect of non-sucrose sweet tasting solution on neonatal heel prick responses. Arch Dis Child 1996;74:F129-31.

26 Skogsdal Y, Eriksson M, Schollin J. Analgesia in newborns given oral glucose. Acta Paediatr 1997;86:217-20.

27 Rushforth JA, Griffiths G, Thorpe H, Levene MI. Can topical lignocaine reduce behavioural response to heel prick? Arch Dis Child 1995;72:F49-51.

28 Larsson BA, Jylli L, Lagercrantz H, Olsson GL. Does a local anaesthetic cream (EMLA) alleviate pain from heel lancing in neonate? Acta Anesthesiol Scand 1995; 39:102831 .

29 McIntosh N, van Veen L, Brameyer H. Alleviation of the pain of heel prick in preterm infants. Arch Dis Child 1994;79:177-81. 